\title{
Area-Based COI-Referred Rotor Angle Index for Transient Stability Assessment and Control of Power Systems
}

\author{
Noor Izzri Abdul Wahab ${ }^{1}$ and Azah Mohamed ${ }^{2}$ \\ ${ }^{1}$ Department of Electrical and Electronic Engineering, Faculty of Engineering, Universiti Putra Malaysia, \\ Serdang 43400, Selangor, Malaysia \\ ${ }^{2}$ Department of Electrical, Electronic and Systems Engineering, Faculty of Engineering and \\ Built Environment, Universiti Kebangsaan Malaysia, Bangi 43600, Selangor, Malaysia
}

Correspondence should be addressed to Noor Izzri Abdul Wahab, izzri@eng.upm.edu.my

Received 28 June 2011; Accepted 2 January 2012

Academic Editor: Gabriel Turinici

Copyright (c) 2012 N. I. Abdul Wahab and A. Mohamed. This is an open access article distributed under the Creative Commons Attribution License, which permits unrestricted use, distribution, and reproduction in any medium, provided the original work is properly cited.

This paper describes an index for judging the severity of transient events of power systems in simulation. The proposed transient stability index, known as the area-based COI-referred rotor angle index, is developed by considering the fact that a large-sized power system is divided into several areas according to the coherency of generators in a particular area. It can be assumed that an equivalent single large machine can represent all the generators in that area. Thus, the assessment of rotor angles for all generators can be simplified by only assessing the index of areas in a power system. The effectiveness of the proposed index in assessing the stability of power systems and its ability in pinpointing the weakest area in the power system is analyzed. Furthermore, this paper developed an emergency control scheme known as the combined UFLS and generator tripping in order to stabilize the system when unstable faults occurred in a power system. The proposed index is used to identify the generator to be tripped when the developed emergency control scheme operates. The performance of the proposed index and the combined UFLS and generator tripping scheme are evaluated on the IEEE 39-bus test system.

\section{Introduction}

Methods normally employed to calculate TSI are by using time domain simulation [1], direct [2-4], and hybrid methods [5-8]. The TSI derived from the time domain simulation method is the rotor angles to assess transient stability of a power system. However, the calculation of relative rotor angles of all generators is very time consuming and therefore not effective and suitable as TSI for real-time applications.

The TSI developed from the direct methods include TEF and Lur'e Type Lyapunov function [3]. On the other hand, the TSI developed from the hybrid methods is such as the 
reduced TEF and the integral square generator angle. A type of hybrid method known as the marginally unstable injection method [9] uses a reduced TEF and a feedback mechanism to provide a more accurate and consistent TSI. Another hybrid method which incorporates the extended equal area criterion method into the time domain simulation has been used to obtain the TSI for classifying whether a power system is stable or unstable [6]. The single machine equivalent method which is also a hybrid method is used for fast computation of TSI and identification of critical machines [7]. Another TSI known as the integral square generator angle index has been developed to measure the severity of transient disturbances and also used as part of transient stability control [5].

From the literature, many works have been carried out in finding a suitable TSI. It is noted that the use of direct TEF method for developing TSI has some disadvantages such as its inaccuracy due to oversimplification on the power system models, nonexistence of energy functions for some power system models, and the need to compute pseudo fault-on trajectory or line search for calculating the stability margin [10]. The most popular method for developing TSI is by employing the hybrid methods. However, some limitations can still be found when using the hybrid method in developing TSI because it also uses the concept of TEF method in analyzing the results generated by the time domain simulation method. Due to the limitations found in the TSI developed from the direct and hybrid methods, a new TSI is proposed for TSA of large-sized power systems for real-time applications. The proposed TSI is known as the area-based COI-referred rotor angle index which is associated with each area of a power grid and is based on an equivalent inertia representing the total inertia of the generators located in that area. The use of area-based COI-referred rotor angles has been illustrated in which the phase angle data are obtained from phasor measurement units located at selected buses in a power system [11]. However, in this work, the rotor angles data are obtained from each generator in the power system. The proposed TSI is developed by considering the fact that a large-sized power system is divided into several areas according to the coherency of generators in a particular area. Assuming that all the generators in an area are coherent following a disturbance, it is assumed that an equivalent single large machine can represent all the generators in that area. Thus, the assessment of rotor angles for all generators in a power system can be reduced to only assessing the index of areas in a power system.

Unlike direct and hybrid methods, the proposed TSI does not use the concept of TEF although the center of inertia (COI) reference frame is used. The derivation of the area-based center of inertia-referred rotor angle index is explained in Section 2. This paper presents the effectiveness of the proposed index in assessing the stability of power systems and its ability in pinpointing the weakest area in the system. Apart from that, an emergency control scheme known as the combined UFLS and generator tripping is developed in order to stabilize the system when unstable faults occurred in a power system. The proposed index is used to identify the generator to be tripped when the developed emergency control scheme operates. The performance of the combined UFLS and generator tripping scheme is compared with the conventional UFLS control scheme. The results show that the combined control scheme performed better. The IEEE 39-bus test system is considered for verification of proposed methods.

\section{Formulation of the Proposed Index}

Before deriving the proposed TSI, the machine equations used to evaluate the dynamic behavior of a power system for transient stability simulation are considered first. The 
differential equations to be solved in power system stability analysis using the time domain simulation method are the nonlinear ordinary equations with known initial values. Using the classical model of machines, the dynamic behavior of an $n$-generator power system can be described by the following equation:

$$
M_{i} \frac{d^{2} \delta_{i}}{d t^{2}}=P_{m i}-P_{e i}
$$

However,

$$
\dot{\delta}_{i}=\omega_{i}
$$

By substituting (2.2) into (2.1), we get

$$
M_{i} \dot{\omega}_{i}=P_{m i}-P_{e i}
$$

where $\delta_{i}$ : rotor angle of machine $i, \omega_{i}$ : rotor speed of machine $i, P_{m i}$ : mechanical power of machine $i, P_{e i}$ : electrical power of machine $i, M_{i}$ : moment of inertia of machine $i$. Equation (2.3) is then solved by using a time domain simulation program through step-bystep integration so as to produce time response of all the state variables. The rotor angles calculated from (2.3) are then used in the computation of the proposed area-based COIreferred rotor angle index. The proposed TSI is associated with each area of a power grid and is based on an equivalent inertia representing the total inertia of the generators located in that area. Assuming that all the generators in an area are coherent following a disturbance, it is reasonable to assume an equivalent single large machine representing all the generators in that area. This can be made possible by deriving the COI, which is very useful information for tracking the stability of interconnected areas. Before defining the COI quantities, the area equivalent rotor angle concept needs to be defined first. For a particular area, with $N$ number of generators, that particular area equivalent rotor angle is the average rotor angle through all $N$ measurements which is given by

$$
\bar{\delta}_{j}=\frac{1}{N} \sum_{i=1}^{N} \delta_{i}
$$

where $\bar{\delta}_{j}$ : area equivalent rotor angle, $\delta_{i}$ : individual rotor angle in a particular area. Assuming a total number of $r$ areas in a power system, the COI of the system can be defined as

$$
\bar{\delta}_{\mathrm{coi}}=\frac{1}{M_{T}} \sum_{j=1}^{r} M_{j} \bar{\delta}_{j}
$$

in which

$$
M_{T}=\sum_{j=1}^{r} M_{j},
$$


where $M_{T}$ : total inertia in a system, $M_{j}$ : jth inertia in an area. The area equivalent rotor angle is then expressed in the COI frame and is given by

$$
\delta_{j}^{\mathrm{coi}}=\bar{\delta}_{j}-\bar{\delta}_{\mathrm{coi}}
$$

The area-based COI-referred rotor angle as given in (2.7) is then used as a TSI in which the behavior of the index is illustrated by plotting against time. From the plot, it can be observed that, if the rotor angle of any area $\left(\delta_{j}^{\text {coi }}\right)$ goes out of step after a fault is cleared, then the area is said to be unstable, whereas, if it remains in equilibrium than the area is said to be stable. The behavior of $\delta_{j}^{\text {coi }}$ when the system is subjected to fault is similar as that of rotor angle of generators in a power system.

The formulation of the area-based COI-referred rotor angle index is fairly simple and straight forward and therefore useful for applications in large-sized power systems. It can be said that the calculation of the proposed TSI combines time domain simulation and direct methods since the proposed TSI used the COI reference frame to calculate the area angle $\left(\delta_{j}^{\text {coi }}\right)$ which is generally synonymous with formulation of TEF and single-machine equivalent methods $[7,12,13]$. However, the formulation of the proposed TSI does not use the concept of the TEF in finding the stability index. As a result, this will eliminate the additional computational burden and modeling limitations usually associated with the TEF method. The area-based COI-referred rotor angle index negates the need to assess all generators rotor angles in a power system, and, therefore, rapid assessments of the whole system after the occurrence of faults can be achieved.

The use of area-based COI-referred rotor angles has been illustrated in which the phase angle data are obtained from phasor measurement units located at selected buses in a power system [11]. In this work, the effectiveness of using the area-based COI-referred rotor angles as a TSI is further explored by verifying it on IEEE 39-bus test system. In this case, the generator rotor angles data are obtained from time domain simulations carried out using the PSS ${ }^{T M}$ E program. The proposed TSI is then compared with the individual rotor angles of each machine in all areas so as to deduce the relationship between the proposed TSI with rotor angles of all machines and to evaluate the accuracy of the TSI in assessing transient stability of a power system.

\subsection{Implementation of the Area-Based COI-Referred Rotor Angle Index for Transient Stability Assessment}

The procedures involved in TSA in power systems using the proposed area-based COIreferred rotor angle as TSI are described as follows.

(i) Run base case power flow simulation to initialize all power system states variable before commencing time domain simulation.

(ii) Create three-phase faults on each transmission line of the test power system. When a three-phase fault occurs at any line in the system, a breaker will operate and the respective line will be disconnected at the fault clearing time which is set at $100 \mathrm{~ms}$ [14]. In some systems, the fault clearing time is not set at $100 \mathrm{~ms}$ but different fault clearing time timings are set for different faults occurring in a system [15]. Normally, the fault clearing time is set randomly by considering whether a power system is stable or unstable after a fault is cleared. 


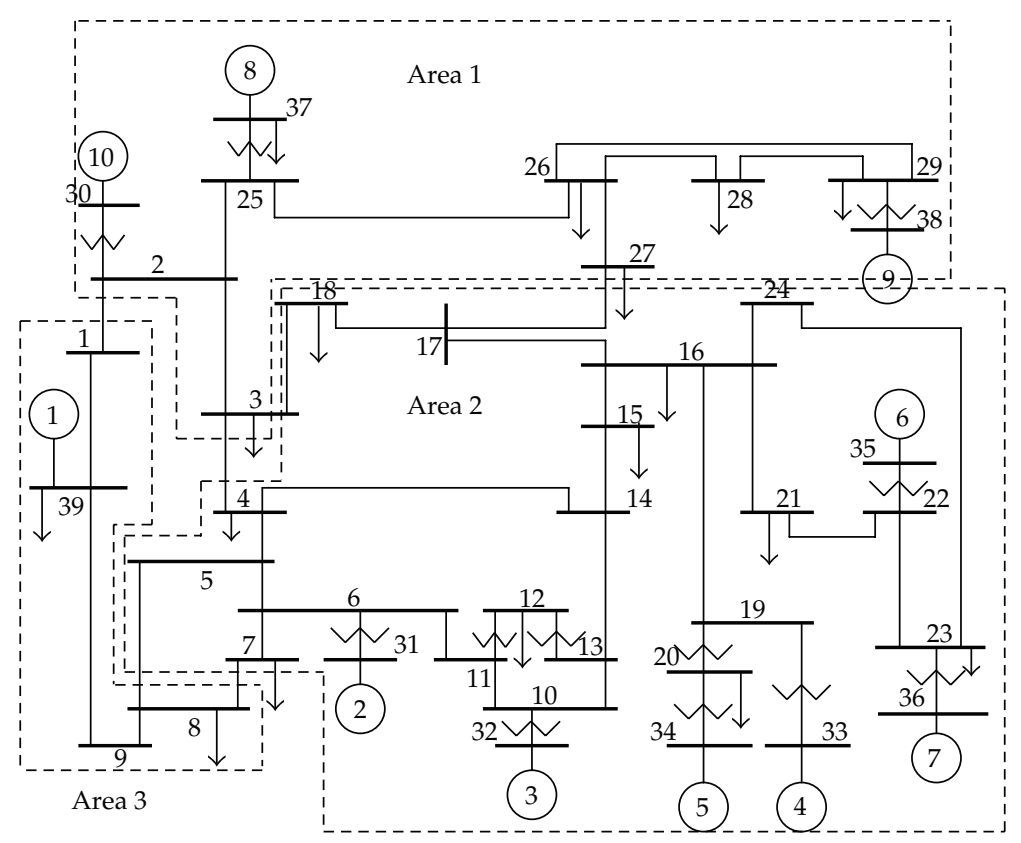

Figure 1: The IEEE 39-bus system.

(iii) Perform time domain simulation by setting a time step, $\Delta t$ of 0.02 seconds. The time frame of interest in the time domain simulation is set at 5 to 15 seconds depending on the size of the test system.

(iv) Use all the rotor angles data collected from the three-phase fault to calculate the area-based COI-referred rotor angle indices.

(v) The area-based COI-referred rotor angle indices are then plotted to illustrate the severity of the contingencies in a power system. If the index exceeds $\pm 180^{\circ}$, the system is unstable, and, otherwise it remains stable.

\subsection{Results of the Area-Based COI-Referred Rotor Angle Index for TSA of IEEE 39-Bus System}

The IEEE 39-bus systems have been used in evaluating the accuracy of the proposed transient stability index and validating the proposed combined load shedding and generator tripping method.

The IEEE 39-bus system, as shown in Figure 1, consists of 10 generators, 12 transformer, 46 transmission lines and 19 loads. The system is divided into three areas; which are Area 1, Area 2, and Area 3 [16]. The load flow and dynamic data of the test system were obtained from Pai [17]. The areas of the IEEE 39-bus are divided according to coherency of generators when subjected to disturbances. Time domain simulation method is used in this work to assess the transient stability of the power system because it is the most reliable, mature and accurate method compared to other method. The differential equations to be solved in transient stability analysis are nonlinear ordinary equations with known initial values. For this purpose, the PSS ${ }^{\mathrm{TM}}$ E software is used. 
In this work, the dynamic performance of the system during disturbances is based on observation of the rotor angle of generators in their respective areas via a time domain simulation method. Three-phase faults are created at various locations in the systems at any one time. In this aspect, the power system goes through prefault, fault-on, and postfault stages [15]. When a three-phase fault occurs at any line in the system, a breaker will operate and the respective line will be disconnected at the fault clearing time (FCT) which is set at $100 \mathrm{~ms}$ [14]. According to Anderson and Fouad [1], if the relative rotor angles remain stable after a fault is cleared, it implies that the power system is stable, but, if the relative angles go out of step after a fault is cleared, it means that the system is unstable. The time step, $\Delta t$, for the time domain simulations is set at 0.02 seconds. The time frame of interest in transient stability studies is usually limited to 3 to 5 seconds following the disturbance; it may be extended to 10 seconds for very large systems with dominant interarea swings [18]. All the rotor angles data collected from all the contingencies are then applied to the proposed TSI. The TSI is then plotted to illustrate the severity of the contingencies on the power system.

The proposed TSI using area-based COI-referred rotor angles are compared with the rotor angles plotted for all the generators in the test systems. The performance of the proposed TSI in assessing the transient stability state of power systems and its ability to determine the weak areas in a power system are presented in this section. The area-based COI-referred rotor angles index is plotted against time using the MATLAB program.

The time taken to run the transient stability simulations is set at 6 seconds considering that it is a small power system. Simulations were carried out using the PSS ${ }^{\mathrm{TM}} \mathrm{E}$ software in which the output data were plotted using the MATLAB program. The proposed TSI based on the area-based COI-referred rotor angles is compared with the rotor angles plotted for all the generators in the system. For illustration purposes, 3 cases of three-phase faults occurring in the power system are considered to prove the accuracy of the proposed TSI.

Case 1. A three-phase fault is created at the transmission line connecting bus 2 and bus 25 (Line 4) in the Area 1. The transmission line is disconnected after the fault is cleared at 100 ms. Figures 2(a), 2(b), and 2(c) show the individual rotor angle plots for each machine in their respective areas, while Figure 2(d) shows the area-based COI-referred rotor angles. It can be seen from Figures 2(a)-2(c) that all the rotor angles in their respective areas increase exponentially. Due to this three-phase fault, the rotor angles increase very quickly and the plots of the angles imply that the system is unstable. The area-based COI-referred rotor angle plot shown in Figure 2(d) is also similar to the individual rotor angle plots in which all the areas COI-referred rotor angles go out of step after the fault has occurred. The angles go out of step when they exceed $180^{\circ}$ in 2 seconds after the fault is cleared. This contingency is considered as a severe contingency because it is said to create a transiently unstable state in the power system. In order to identify the weakest area in the system, Figure 2(d) is enlarged as shown in Figure 3. The arrow in the figure shows that the Area 1 COI-referred rotor angle is the first to intercept the $180^{\circ}$ line. This means that it is the first area to go out of step, and, therefore, it is considered as the weakest area in the power system. The power system is said to become unstable when all the COI-referred rotor angles go out of step which is after 2.75 seconds.

Case 2. A three-phase fault is created at the transmission line connecting bus 4 and bus 14 (Line 8) in the Area 2. The transmission line is disconnected after the fault is cleared at $100 \mathrm{~ms}$. Figures $4(\mathrm{a})-4$ (c) show the 4 plots consisting of the individual rotor angle plots for each machine in their respective areas, and Figure 4(d) shows the area-based COI-referred rotor 


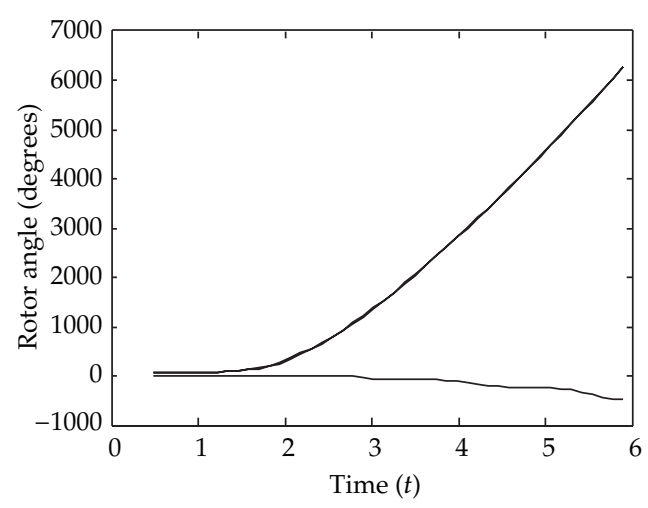

(a) Area 1

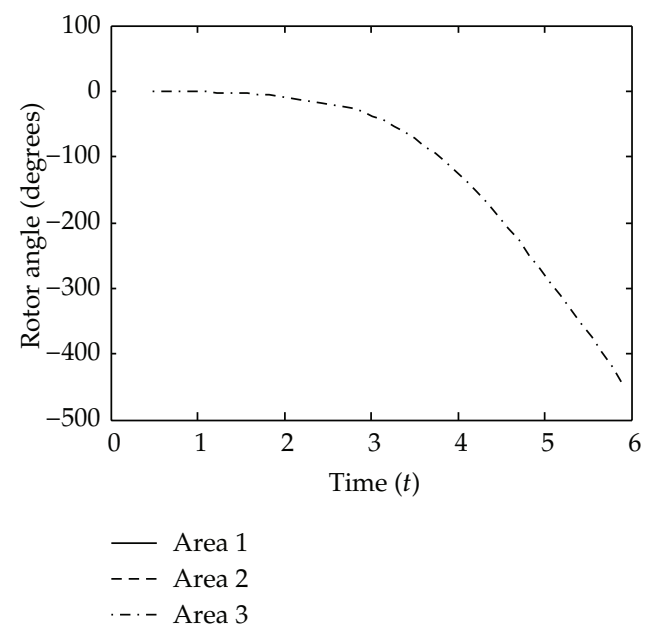

(c) Area 3

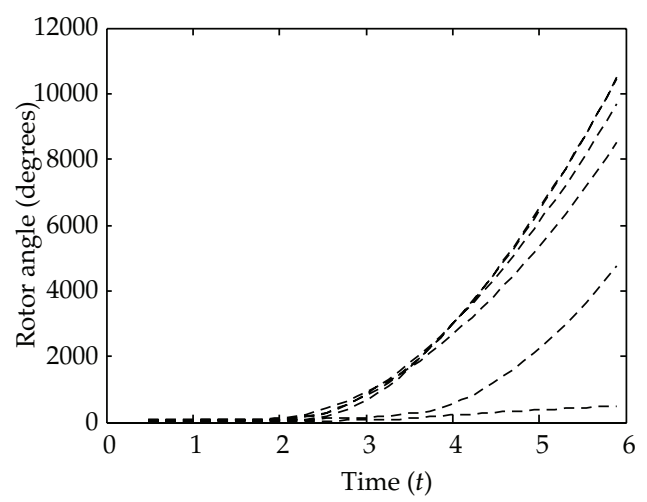

(b) Area 2

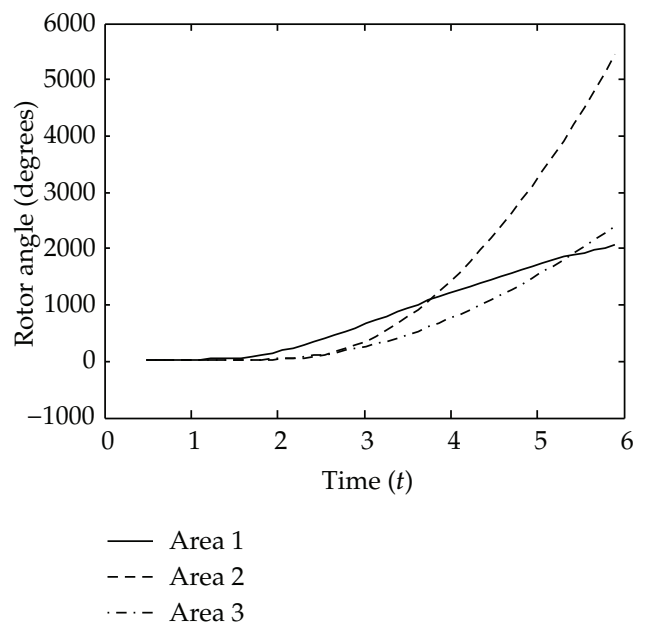

(d) Area-based COI-referred rotor angles index

Figure 2: Case 1: The system becomes unstable due to a fault at Line 4 (Area 1).

angles plots. From the plots, it shows that the three-phase fault at Line 8 does not affect the system stability since the individual rotor angle plots of all machines in their respective areas do not violate the stability limit of the power system. The area-based COI-referred rotor angles plots are also consistent with the individual rotor angles plots. Thus, for a three-phase fault at Line 8, the system is said to remain in synchronism after the fault has occurred, and this illustrates a transiently stable case.

Case 3. A three-phase fault is created at the transmission line connecting bus 5 and bus 6 (Line 9) in the Area 1. After the fault is cleared at $100 \mathrm{~ms}$, the transmission line is disconnected. Figure 5 shows the 4 plots consisting of the individual rotor angle plots for each machine in their respective areas (Figures 5(a)-5(c)) and the area-based COI-referred rotor angles (Figure 5(d)). It can be seen from Figures 5(a)-5(c) that all the rotor angles in their respective areas increase rapidly. Due to this three-phase fault, the rotor angles increase very quickly and the plots of the angles imply that the system is unstable. The pattern of the area-based COI-referred rotor angles plot shown in Figure 5(d) is also similar with the individual rotor angle plots. All the COI-referred rotor angles go out of step (exceed $180^{\circ}$ ) in 2 seconds after the fault is cleared. This contingency is considered as a severe contingency because unstable 


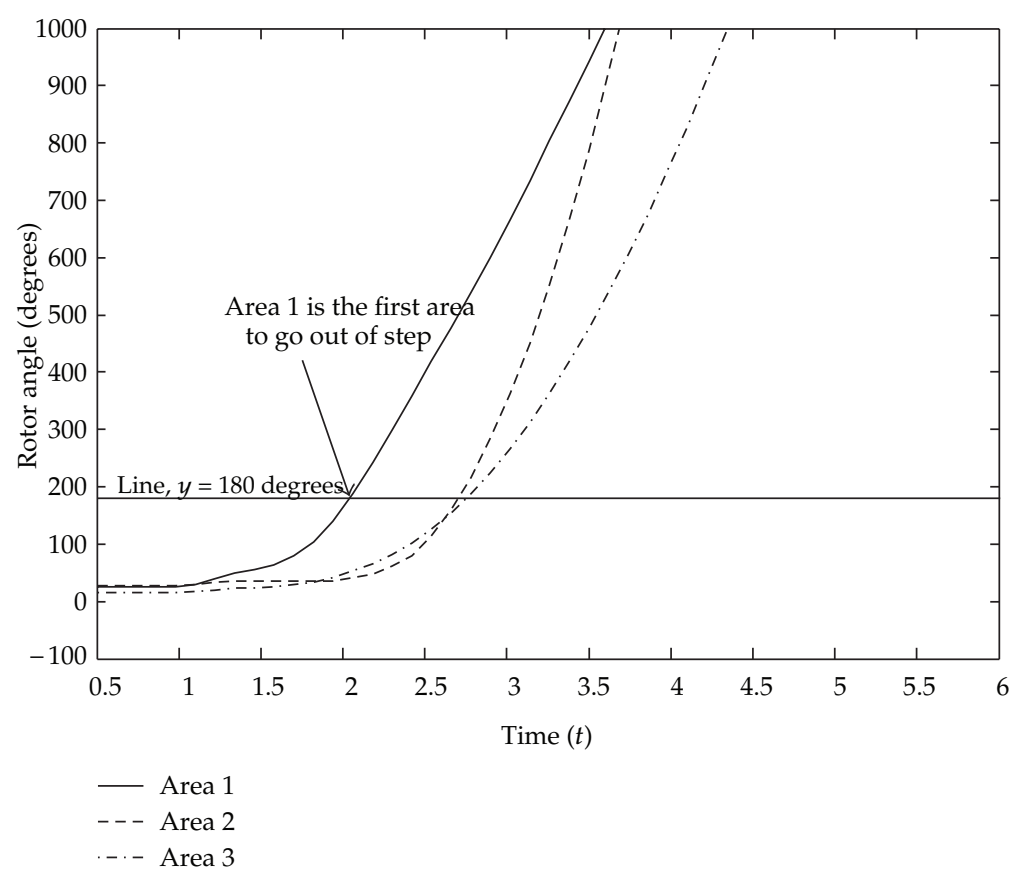

Figure 3: The Area 1 COI-referred rotor angle goes out of step the earliest.

state is observed in the system. In order to identify the weakest area, a larger version of Figure 5(d) is plotted as shown in Figure 6. The arrow in the figure shows that the Area 2 COI-referred rotor angle is the first to intercept the $180^{\circ}$ line which indicates that it is the first area to go out of step after the fault is cleared. The power system becomes unstable when all the COI-referred rotor angles go out of step after 3.7 seconds.

\section{Transient Stability Control Using Underfrequency Load Shedding Scheme}

When a severe transient disturbance occurs in a power system, the system frequency would decline due to insufficient amount of generated power to meet the load demand. The frequency decline is due to generators slowing down because part of the energy from the generators' rotating power is used to compensate for deficiency in electrical energy [19]. When a power system changes from normal to underfrequency emergency condition, an underfrequency load shedding (UFLS) scheme becomes of vital importance for secure operation of a power system. UFLS is defined as a coordinated set of controls which results in a decrease of electrical loads in a power system [20]. An UFLS system is designed to retrieve the balance of generation and demand following a severe disturbance [21]. In this way, whenever the frequency of a system falls below its predetermined threshold, some parts of the system loads are shed in a few steps after an intentional time delay. The relationship that shows the variation of frequency with time, following a sudden variation in load and/or generation, is derived by first considering

$$
\frac{G H}{\pi f_{0}} \frac{d^{2} \delta}{d t^{2}}=P_{a}
$$




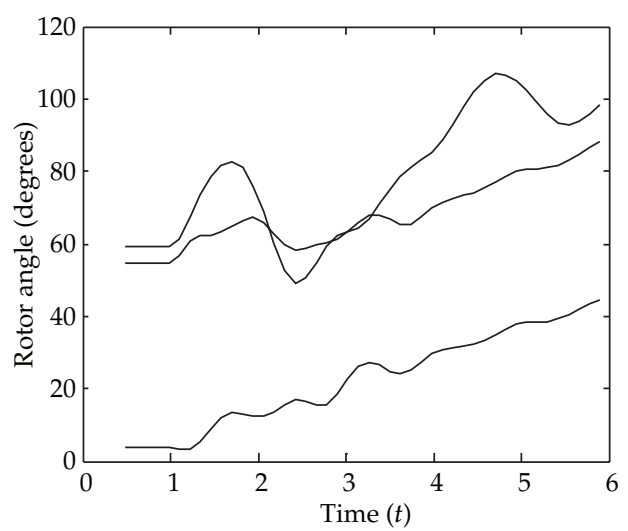

(a) Area 1

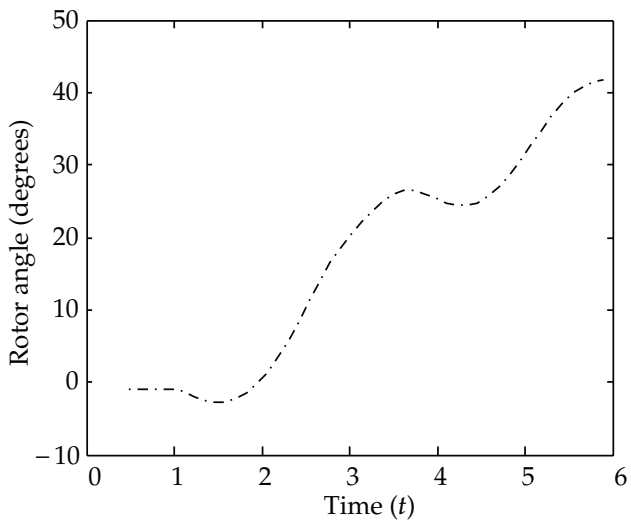

- Area 1
- - - Area 2
-. - Area 3

(c) Area 3

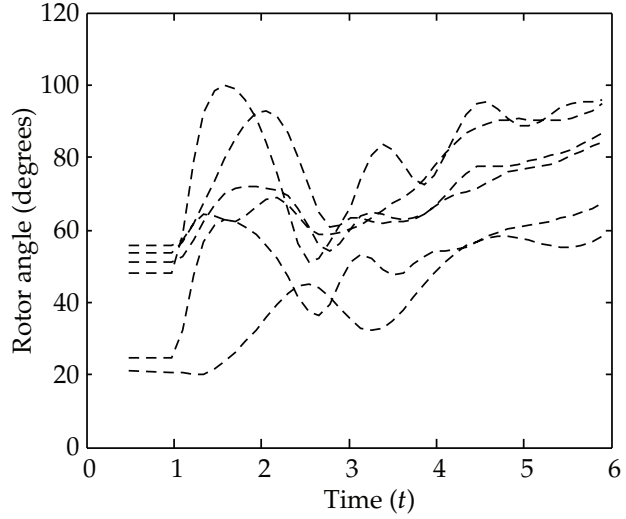

(b) Area 2

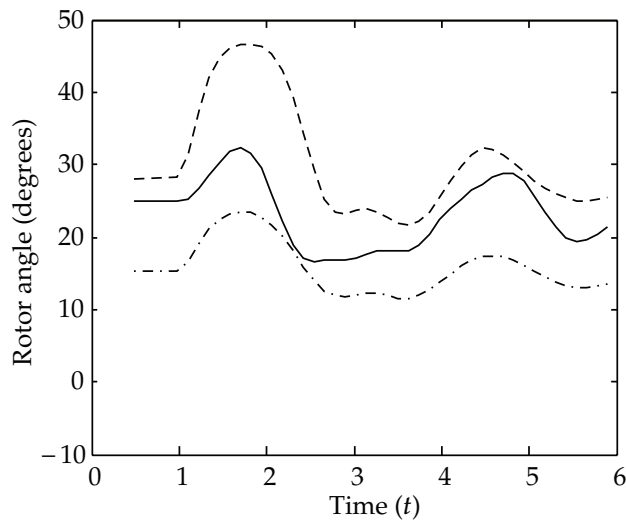

- Area 1

- - Area 2

-..- Area 3

(d) Area-based COI-referred rotor angles index

Figure 4: Case 2: the system remains stable after a fault at Line 8 (Area 2).

where $G$ : nominal MVA of generator, $H$ : inertia constant, $\delta$ : generator rotor angle, $f_{0}$ : nominal frequency, $P_{a}$ : net accelerated or decelerated power. Consider the generator speed variation due to a disturbance which is given by

$$
\omega=\omega_{0}+\frac{d \delta}{d t}=2 \pi f
$$

where $\omega_{0}$ is the synchronous speed. Differentiating (3.2) with respect to time,

$$
\frac{d \omega}{d t}=\frac{d^{2} \delta}{d t^{2}}=2 \pi \frac{d f}{d t}
$$




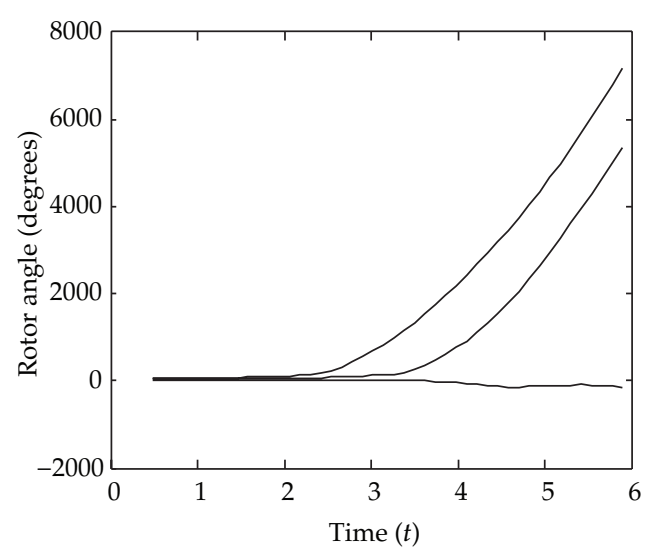

(a) Area 1

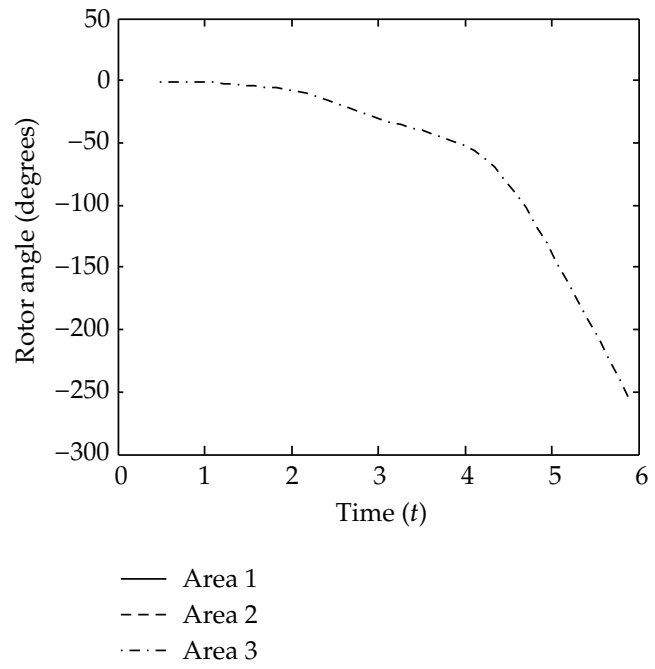

(c) Area 3

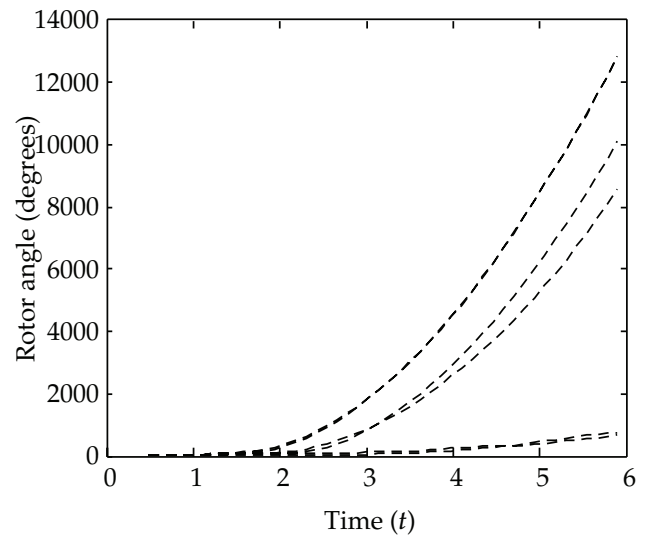

(b) Area 2

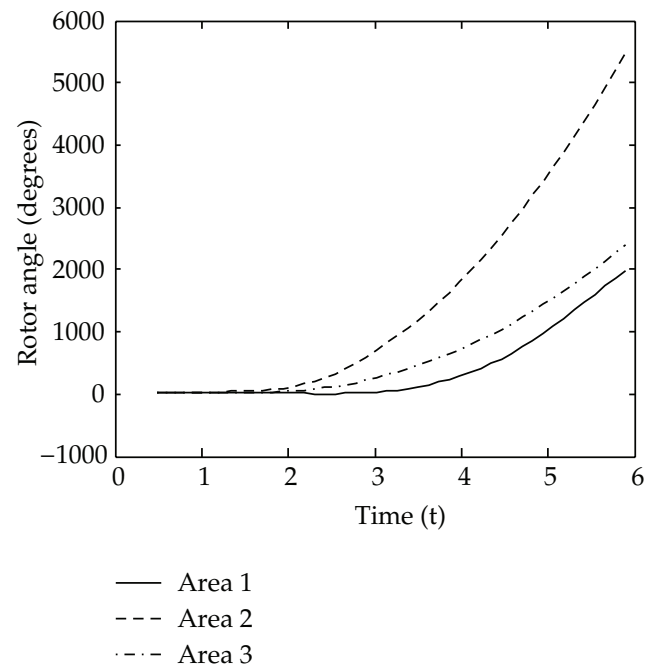

(d) Area-based COI-referred rotor angles index

Figure 5: Case 3: the system becomes unstable due to a fault at Line 9 (Area 2).

Substituting (3.3) in (3.1), we get

$$
\frac{d f}{d t}=\frac{P_{a} f_{0}}{2 G H}
$$

Equation (3.4) defines the rate of change of frequency in $\mathrm{Hz}$, which can be used for an individual generator or for an equivalent which represents the total generation in a system. For equivalent case, the inertia constant $(H)$ can be derived from the following:

$$
H=\frac{H_{1} M V A_{1}+H_{2} M V A_{2}+\cdots+H_{n} M V A_{n}}{M V A_{1}+M V A_{2}+\cdots+M V A_{n}},
$$




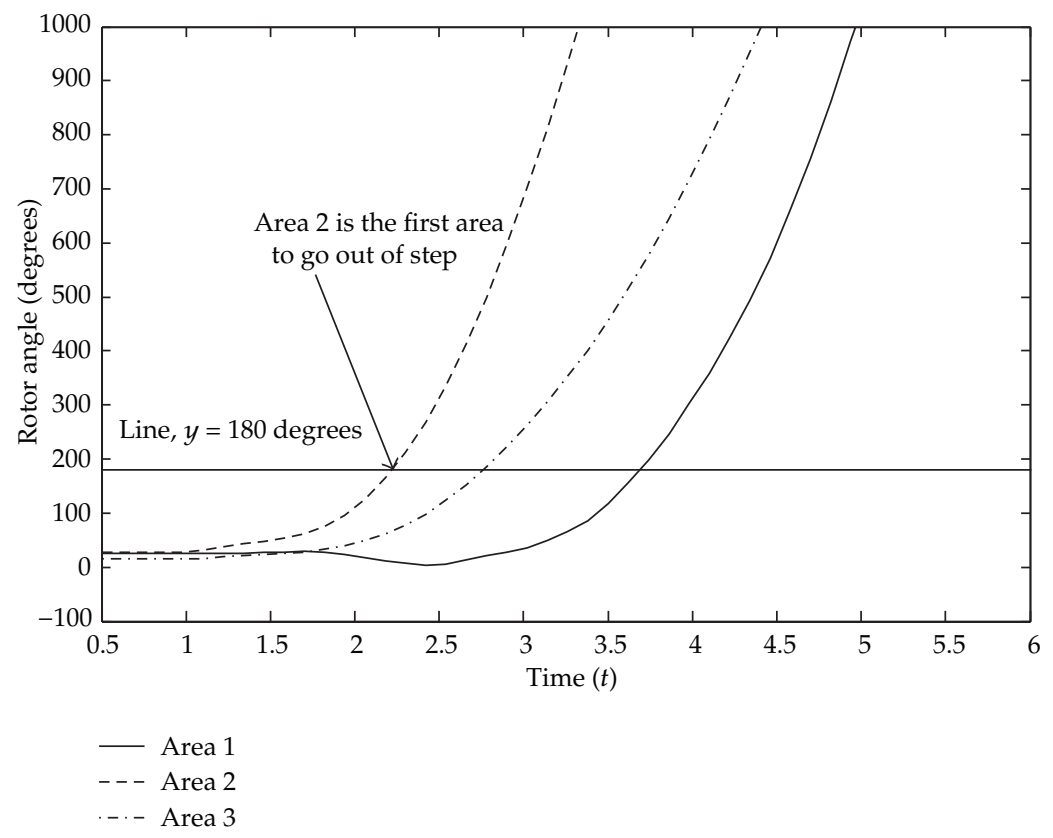

Figure 6: The Area 2 COI-referred rotor angle goes out of step the earliest.

where $n$ is the number of generators in a power system. The accelerating power, $P_{a}$, in (3.4) is responsible for the rate of change of frequency due to disturbances in a power system. $P_{a}$ can be written as

$$
P_{a}=P_{m}-P_{e}
$$

where $P_{m}$ : mechanical power entering the generator, $P_{e}$ : electrical power leaving the generator. A power system is said to be stable when $P_{a}$ equals to zero which means that there is no change in the frequency. In the case of overload, when $P_{e}>P_{m}$, which would result in $P_{a}<0$, then there will be a drop in the power system frequency.

The variation of system frequency during such a disturbance is not a smooth rate of decay but rather is oscillatory in nature because of the interaction of the interconnected generators. When the generators operating below its nominal speed at a reduced frequency, a cumulative damage can be produced due to excessive vibration. Table 1 shows the time limits for the generators operating at different frequencies below their rated frequency [22]. From Table 1, if the time limits are not heeded and the frequency is not recovered to their permitted level, the related generator in a power system will trip which would increase the power imbalance in the system. This would decrease the frequency further and cause other generators in the system to trip which would lead to cascading outage of generators and eventually the power system encounters a widespread blackout [21].

\subsection{Design of Underfrequency Load Shedding Scheme}

The steps involved in designing an UFLS scheme are described as follows. 
Table 1: Typical time limits for the operation of generators at frequencies below their rated frequency.

\begin{tabular}{lc}
\hline Percentage of rated frequency at full load $(\%)$ & Maximum permissible time (minutes) \\
\hline 99.0 & Continuous \\
97.3 & 90 \\
97.0 & 10 \\
96.0 & 1 \\
\hline
\end{tabular}

(i) Determine the anticipated overload which is an important parameter to represent the protection to be provided and the amount of service that will be disrupted in the event of overload. The calculation of the anticipated overload (L) in per unit is given by

$$
L=\frac{\text { Total Load }- \text { Total Generation }}{\text { Total Generation }}
$$

From (3.7), if a system is balanced, there will be no anticipated overload. However, a loss of $33 \%$ of total generation due to a fault occurring in a system will lead to $50 \%$ overload and a loss of $50 \%$ of the total generation will lead to $100 \%$ overload. The value of the anticipated overload greater than $50 \%$ is not recommended due to possible over load shedding for less severe unstable faults [21].

(ii) Determine the number of load shedding steps. A typical load shedding scheme will consider three to six stages [21]. The UFLS scheme implemented in this work utilizes 4 stages of load shedding considering $20 \%, 20 \%, 30 \%$, and $30 \%$ of the total load to be shed. The amount of load to be shed for the first-stage is $20 \%$, second stage is $20 \%$ (the total load shed in the second stage is $40 \%$, which includes the amount of load shed in the first-stage), third stage is 30\% (total load shed at this stage is $70 \%$, which includes first and second stages), and final stage is $30 \%$ (total load shed is $100 \%$, which includes amount of load shed of first, second, and third stages) of the total amount of load to be shed. It should be noted that the total amount of load to be shed is according to the number of stages needed in order for an unstable system to recover to a stable state. The duration between consequence load shedding stages is between 2 to 3 cycles [21].

(iii) Determine the amount of load to be shed in order to maintain the system's frequency above its minimum permissible frequency. The total load to be shed in per unit is given by [21]

$$
L D=\frac{L /(1+L)-d\left(1-f_{\min } / f_{n}\right)}{1-d\left(1-f_{\min } / f_{n}\right)}
$$

where $L$ : anticipated overload in p.u., $f_{\min }$ : minimum permissible frequency, $f_{n}$ : nominal frequency, $d$ : load reduction factor. The minimum permissible frequency $\left(f_{\min }\right)$ used by most utilities is $49.3 \mathrm{~Hz}$ for $50 \mathrm{~Hz}$ nominal frequency system [20].

(iv) Determine the load buses where loads are to be shed. The total load to be shed calculated in (iii) is selected from the load buses whose voltages are severely affected by an unstable fault occurring in a power system. The voltage in the area 
where an unstable fault occurs will decline faster than other areas in a power system. Thus, loads that are located near to the fault location in a particular area will be the most affected load compared to loads located far from the fault location [23]. The loads in the affected area are ranked by monitoring the voltage decline at their respective buses at the time when a fault occurs in a power system. The buses with greater voltage decline will be ranked higher than those buses with lesser voltage decline because voltage decline at buses located nearer to the fault will be greater than at buses located far from the fault. From the ranking of the load buses, the higher ranked load buses are selected for load shedding at these buses. Thus, the UFLS scheme is implemented by first shedding loads at the load buses near to the fault location and then only shed loads at buses further away from the fault location.

\subsection{UFLS Scheme Implementation Procedure}

The procedures for implementing an UFLS scheme are described as follows.

(i) Calculate the amount of load to be shed, LD, using (3.8). If the anticipated overload is $33 \%$, $L$ would be 0.5 , and, assuming that $d=1.7$ and $f_{\min }=49.3 \mathrm{~Hz}$, the amount of load to be shed is 0.317 p.u.

(ii) Run dynamic simulations of a power system by considering various contingencies. In this work, three-phase faults occurring at each line in a power system are considered. Identify the unstable cases by using the proposed area-based COIreferred rotor angle index.

(iii) For the unstable cases, rank the loads in the system according to the severity of the voltage decline at the load buses due to a fault. The total load to be shed (LD) is then calculated.

(iv) From the ranking of loads in (iii), divide the total load to be shed in 4 stages of load shedding of $20 \%, 20 \%, 30 \%$, and $30 \%$. The first-stage of the UFLS scheme would be implemented at the loads most affected by the voltage decline, and the subsequent stages are the less affected loads.

(v) Run the dynamic simulation again for the unstable cases only but this time with the UFLS control scheme. In the initial UFLS scheme, shed the first-stage UFLS at a fault clearing time which is set at $100 \mathrm{~ms}$. Monitor the area-based COI-referred rotor angle index in order to verify whether the power system manages to recover to a stable state after performing the first-stage load shedding. If the system becomes stable after the first load shedding, then stop the UFLS control. However, if the system is still not stable, then continue with the subsequent second, third, and fourth stage of load shedding. At each stage, the proposed index is calculated to monitor the system stability status. If, at any stage, the system recovers to a stable state, then the UFLS scheme is stopped, otherwise, it will continue until the fourth stage by which, at this stage, the system should recover to a stable state. 


\section{Combined Underfrequency Load Shedding with Generator Tripping Scheme}

Generator tripping is considered as an effective method of transient stability control [24]. When a transmission line is opened due to a line fault, the excess generation in a power system may cause all of the generators in the system to lose synchronism and lead the system to an unstable condition. Tripping one or more generators from a group of generators in a system may reduce the system total inertia which would prevent the system from loss of synchronism. In this work, generator tripping and UFLS scheme are combined to provide transient stability control of power systems. From now onwards in the text, the combined UFLS and generator tripping scheme will be known as the combined control scheme. By employing UFLS alone as a form of transient stability control, the loss of loads in a power system will be greater than when it is combined with generator tripping. This is because generator tripping does not cause loss of load in a power system but a reduction in the system total inertia which may reduce the effect of a fault. In the proposed combined method for transient stability control, the priority is to first trip a generator and then followed by the UFLS scheme if needed when an unstable condition still prevails.

In generator tripping, the most important step is to identify which generators are to be tripped in order to reduce the effect of instability in a power system [24]. The proposed areabased COI-referred rotor angle index is used to identify the weakest area in a power system due to an unstable fault. The identified weakest area consists of a group of generators located in that area. In order to identify the generator to be tripped in the weakest area, individual COI-referred rotor angles for each generator need to be calculated. Thus, by employing the proposed area-based COI-referred rotor angle index, the weakest area is identified, and, by using the individual COI-referred rotor angle for each generator in the weakest area, the first generator that goes out of step (rotor angle exceeds $\pm 180^{\circ}$ ) is identified.

In order to determine the generator that goes out of step due to an unstable fault, the COI of a system given by (2.5) in Section 2 is rewritten as

$$
\bar{\delta}_{\text {coi }}=\frac{1}{M_{T}} \sum_{j=1}^{r} M_{j} \bar{\delta}_{j}
$$

in which

$$
M_{T}=\sum_{j=1}^{r} M_{j}
$$

where $M_{T}$ : total inertia in a system, $M_{j}$ : jth inertia in an area, $\bar{\delta}_{j}$ : area equivalent rotor angle, $r$ : total number of areas in the power system.

The individual rotor angle of a generator in the weakest area, $k$, expressed in the COI frame can be defined as,

$$
\delta_{k}^{\mathrm{coi}}=\delta_{k}-\bar{\delta}_{\mathrm{coi}}
$$

where $\delta_{k}$ : individual generator's rotor angle in the weakest area. 
By this definition, the generator in the weakest area to be tripped would be the first generator to go out of step with its individual COI-referred rotor angle exceeds the $\pm 180^{\circ}$. follows.

The procedures involved in identifying the generator to be tripped are given as

(i) Run time domain simulations by considering three-phase faults as contingencies and obtain the rotor angles responses.

(ii) Calculate and plot the area-based COI-referred rotor angle indices for all the areas in the system.

(iii) Identify the weakest area based on the curves of the area-based COI-referred rotor angle index that goes out of step (exceeds $\pm 180^{\circ}$ ).

(iv) Calculate the individual COI-referred rotor angle for each generator in the weakest area using, $\delta_{k}^{\text {coi }}=\delta_{k}-\bar{\delta}_{\text {coi }}$.

(v) Rank the generators in the weakest area based on the generators' individual COIreferred rotor angles that go out of step (exceeds $\pm 180^{\circ}$ ) the earliest.

(vi) Trip the highest ranking generator identified in (v) for the proposed generator tripping scheme.

\subsection{Implementation Procedures of the Combined UFLS with Generator Tripping Scheme}

The implementation procedures for UFLS combined with generator tripping for transient stability control are given as follows.

(i) Run time domain simulation for the contingency that causes instability in a power system. From the simulations, obtain the rotor angles and all the frequency responses of the generator buses.

(ii) Implement generator tripping. If the system still remains unstable after generator tripping, implement the UFLS scheme.

(iii) For the generator tripping part, rank the generators and identify the weakest area in the system using the proposed area-based COI-referred rotor angle indices. Determine the generator to be tripped based on the individual COI-referred rotor angle.

(iv) Trip the generator identified in (iii) at a fault clearing time which is set at $100 \mathrm{~ms}$. Monitor the area-based COI-referred rotor angle indices to determine whether the power system manages to recover to a stable state after performing the generator tripping. If the system is stable after the generator is tripped, then stop the combined control scheme. However, if the system is still unstable, then proceed with the UFLS.

(v) For UFLS, rank the loads in a power system based on the severity of voltage decline at the load buses due to a fault. From the ranking of loads, implement UFLS at the loads most affected by the voltage decline. The loads are shed in four stages considering $20 \%, 20 \%, 30 \%$ and $30 \%$ of the total load to be shed. 


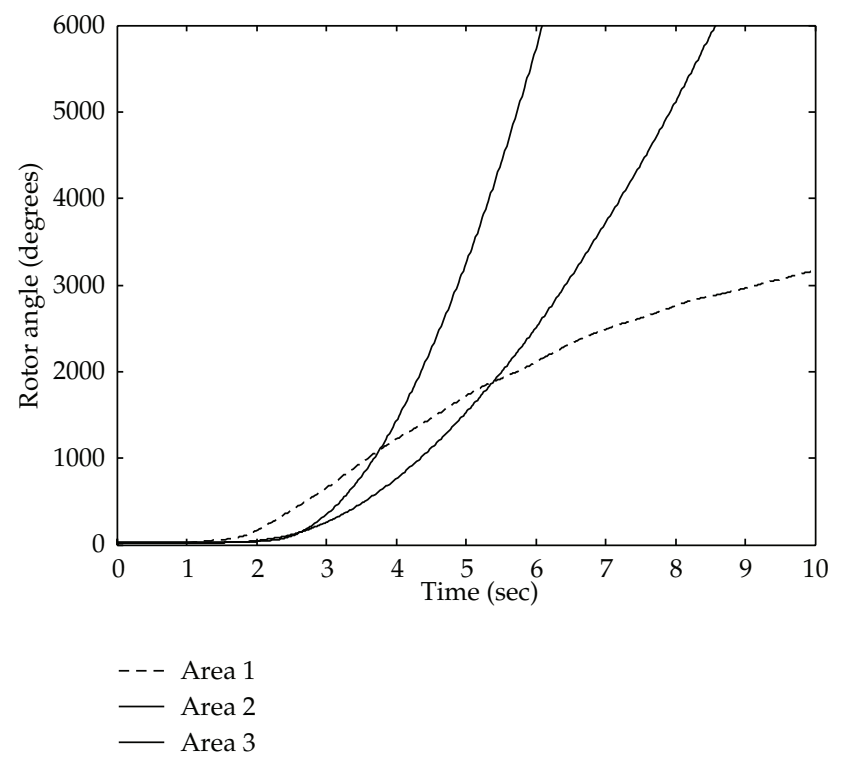

Figure 7: Case 1: all area rotor angles go out of step due to the fault at line 4 .

\section{Results of the Transient Stability Emergency Control Using UFLS and Combined Control Schemes}

In this section, the performance of the proposed combined scheme is compared to the conventional UFLS scheme for transient stability control (TSC) of the IEEE 39-bus system. For illustration purposes, 2 unstable cases are selected in order to show the effectiveness of the proposed combined control scheme compared to the conventional UFLS control scheme.

\subsection{Comparisons of the Results for Transient Stability Emergency Control Using UFLS and Combined Schemes}

Simulations were carried out using the PSS ${ }^{\mathrm{TM}} \mathrm{E}$ software, and the output results were plotted using the MATLAB program. The time taken to run the transient stability simulations is set at 10 seconds considering that it is a small power system. The results of the combined control scheme are compared with the results of the conventional UFLS scheme. For UFLS, the total load to be shed for the 39-bus system is 0.32 p.u. or 2131.3 MVA and four stages of UFLS are implemented at $20 \%, 20 \%, 30 \%$, and $30 \%$ of the total load with shed load values of 426.3 MVA, 426.3 MVA, 639.4 MVA, and 639.4 MVA, respectively.

Case 1. A three-phase line fault is created at line 4 in the system. After $100 \mathrm{~ms}$, the fault is cleared followed with the disconnection of line 4 . Figure 7 shows the plot of the area-based COI-referred rotor angle indices of the test system. From the plot, it can be seen that the rotor angles of each area goes out of step after the fault is cleared and the system becomes unstable. Due to the fault, the buses average frequency declines as shown in Figure 8.

In order to prevent the system from becoming unstable after the fault is cleared, the conventional UFLS control scheme and the combined control scheme are applied separately 


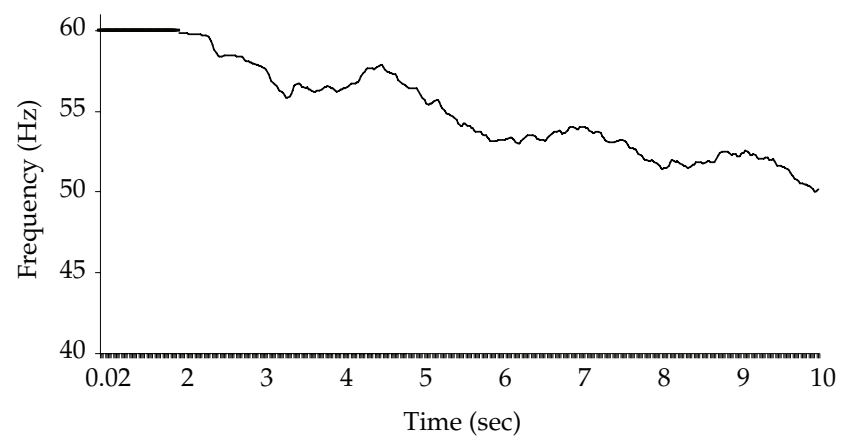

Figure 8: The buses average frequency decline due to the fault at line 4 .

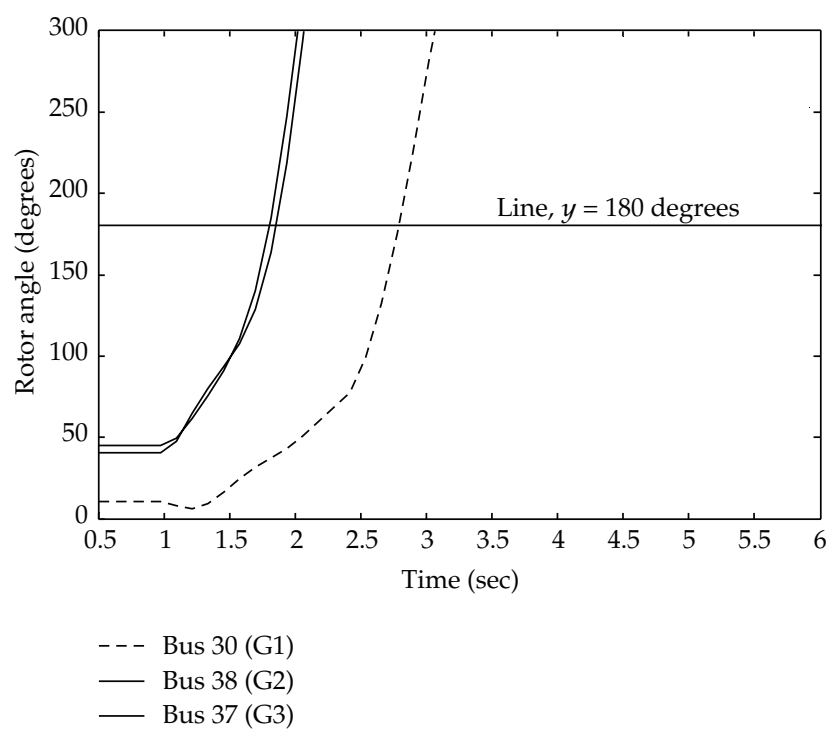

Figure 9: Individual COI-referred rotor angle of generators in Area 1.

to the system. For this case, 3 stages of the UFLS are required for the system to remain stable after the fault is cleared. As for when employing the combined control scheme, before the proposed method is employed, the generator to be tripped is first identified using the individual COI-referred rotor angle method. Since the fault is located at Area 1, therefore the individual rotor angle of generators in Area 1 is plotted as shown in Figure 9. From the plot, the generator located at bus 37 is chosen as the generator to be tripped since it is the first generator to exceed $180^{\circ}$. For Case 1, 3 stages of the combined control scheme are required for the system to maintain its stability after the fault is cleared.

Figure 10 shows that, due to the application of both the, conventional UFLS scheme and the combined control scheme, the system remains stable after the fault is cleared. From the figure, it can be seen that the rotor angles swing in the beginning, but, after sometime the swings subside and the system recovers to its stable state. The average frequency of buses in the system remained at $60 \mathrm{~Hz}$ as shown in Figure 11.

The proposed combined UFLS and generator tripping control scheme gives better performance compared to the conventional UFLS control scheme in terms of amount of 


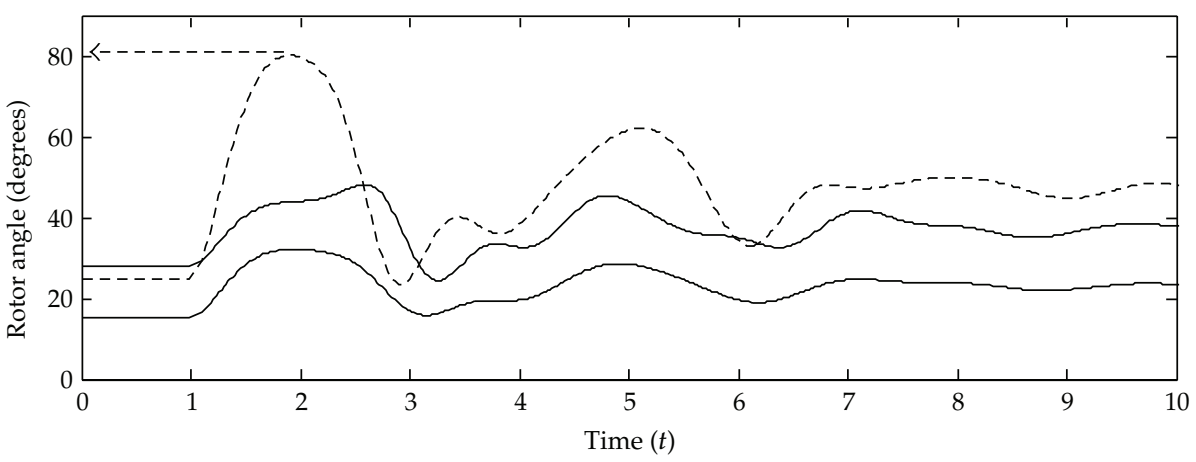

(a) UFLS scheme

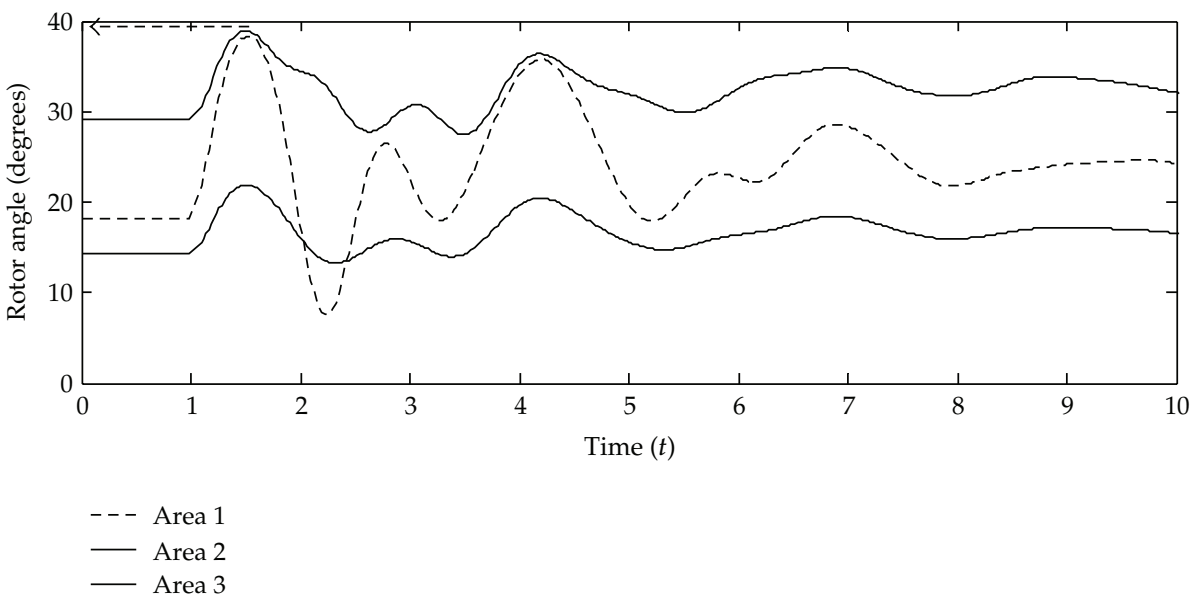

(b) Combined UFLS with generator tripping scheme

Figure 10: The system remains stable after applying both schemes.

load shed and the angle deviation. The amount of load shed is 981.9 MVA when the combined control scheme is employed, whereas 1675.5 MVA load needs to be shed when the conventional UFLS scheme is employed. Comparing Figures 10(a) and 10(b), the maximum angle deviation for the affected Area 1 is $80^{\circ}$ for the conventional UFLS and $38^{\circ}$ for the combined scheme (showed by dashed arrows) which means that lower stress is exerted from the system to the generators in Area 1 when the combined scheme is employed to allow the system to recover to its stable state.

Case 2. A three-phase fault is created at the transmission line connecting bus 13 and bus 14 (Line 18) in Area 2. After $100 \mathrm{~ms}$, the fault is cleared while Line 18 is disconnected. Figure 12 shows the plot of the area-based COI-referred index which indicates that the system becomes unstable after the fault is cleared. Due to the fault, the average bus frequency is deteriorating as shown in Figure 13.

The conventional UFLS control scheme and the combined control scheme is applied separately to the system in order to prevent the system from becoming unstable after the fault is cleared. For this case, 2 stages of the UFLS are required for the system to remain stable because the rotor angles do not go out of step, thus indicating that the system is stable. As 


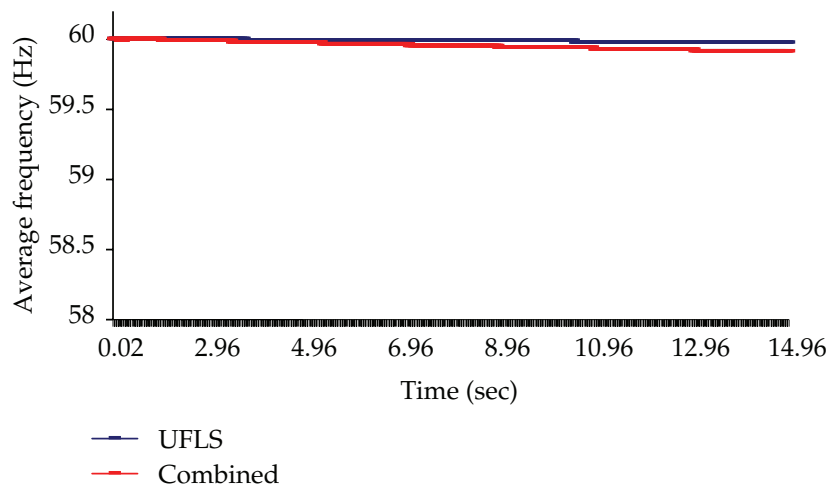

Figure 11: Average frequency responses when both schemes are applied.

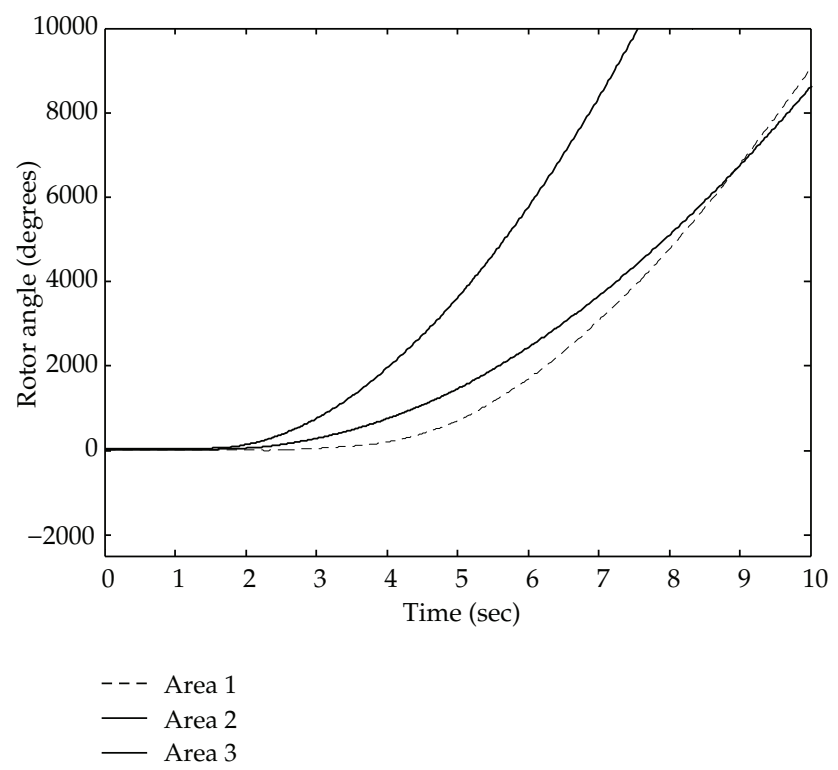

Figure 12: Case 2: the system becomes unstable due to the fault at Line 18.

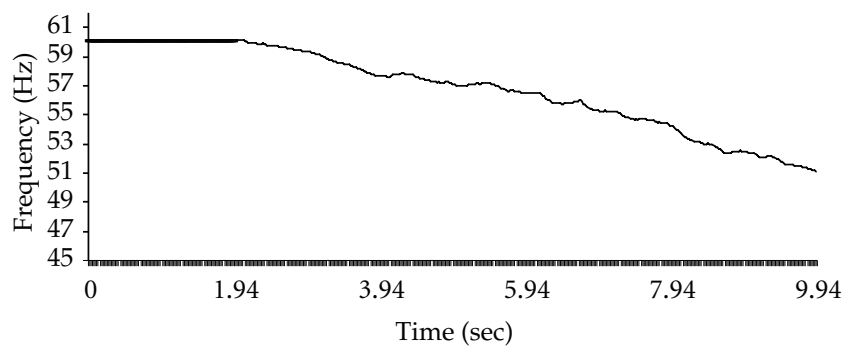

Figure 13: The average bus frequency decline due to a fault at Line 18. 


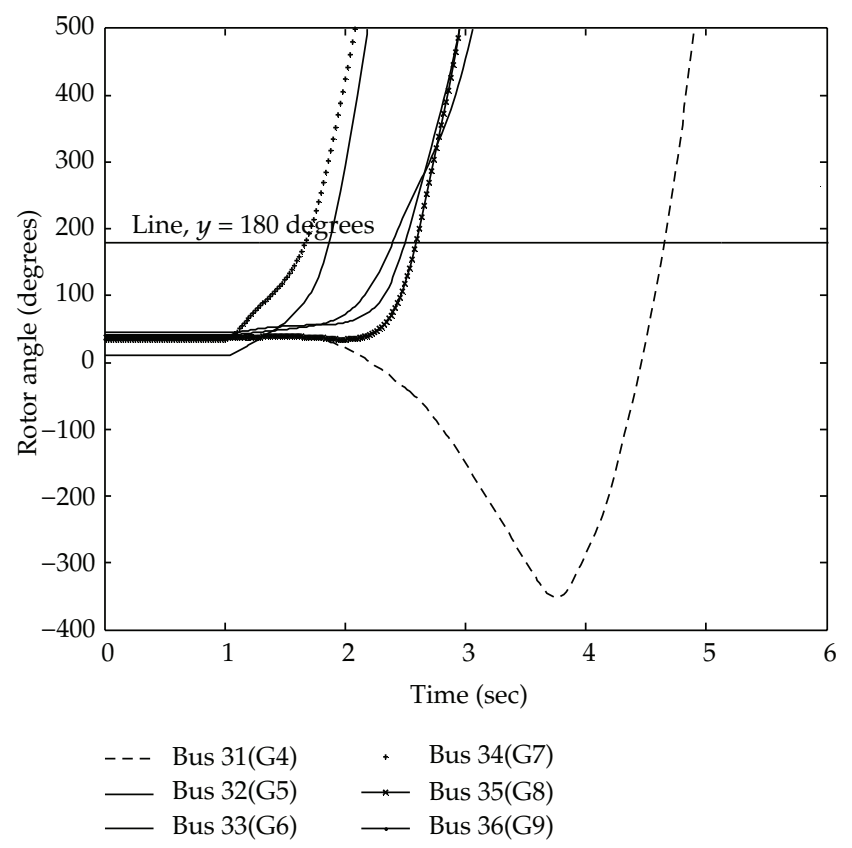

Figure 14: Individual COI-referred rotor angles of generators in Area 2.

for when employing the combined control scheme, before the proposed method is employed, the generator to be tripped is first identified using the individual COI-referred rotor angle method. Since the fault is located at Area 2, therefore the individual rotor angle of generators in Area 2 is plotted as shown in Figure 14. From the plot, the generator at bus 34 (G7) is chosen as the generator to be tripped; since it is the first generator to go out of step. For Case 2,2 stages of the combined control scheme are required for the system to maintain its stability after the fault is cleared.

Figure 15 shows the plot of the area-based COI-referred rotor angle index of the system when the conventional UFLS and combined control schemes are applied. From Figure 15, it is noted that the subsequent angle swings of the COI-referred rotor angles are lower than the initial angle swings for all areas. The average frequency of the system buses remained at $60 \mathrm{~Hz}$ throughout as shown in Figure 16.

Comparing the performance of both control schemes, the amount of load shed is 430 MVA when the combined control scheme is employed whereas 980.9 MVA load needs to be shed when the conventional UFLS scheme is employed. In terms of maximum angle deviation, for the conventional UFLS, the maximum angle deviation for the affected Area 2 is $39^{\circ}$ and $32^{\circ}$ (showed by dashed arrows) for the proposed combined control scheme. This means that lower stress is induced for the generators in Area 2 when the proposed control scheme is employed.

\section{Conclusion}

In this paper, a new TSI called area-based COI-referred rotor angle index is developed for assessing transient stability of large power systems. The new TSI is associated with each area 


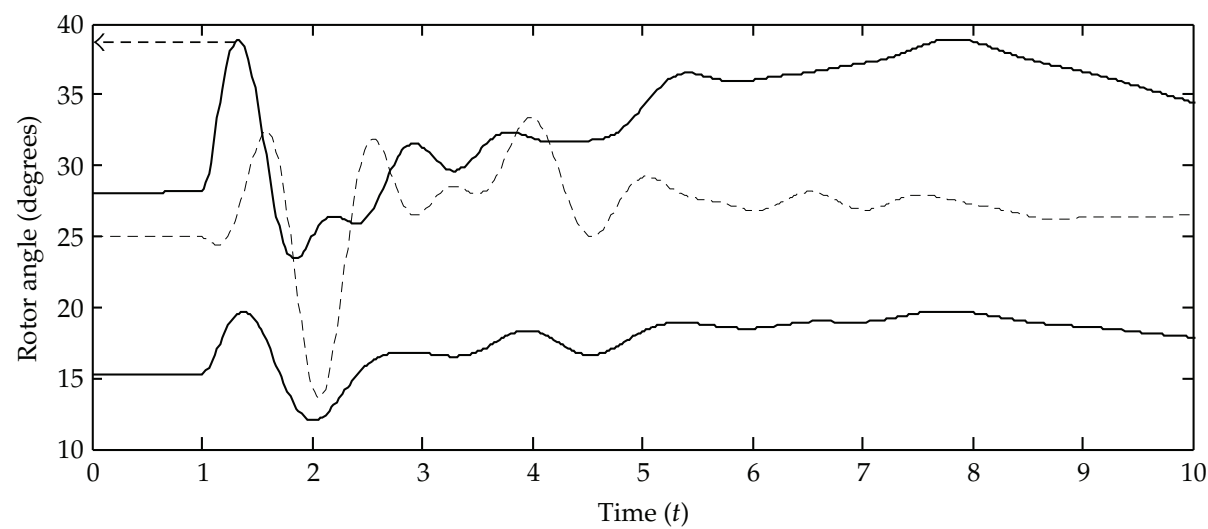

(a) UFLS scheme

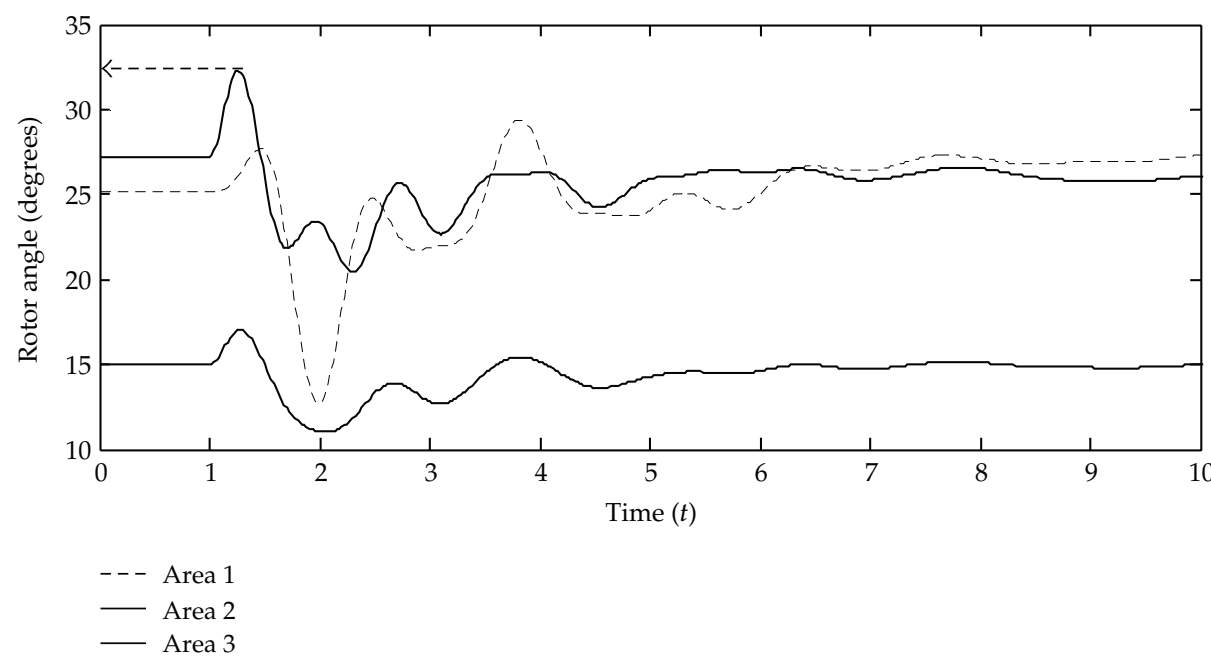

(b) Combined UFLS with generator tripping scheme

Figure 15: The system remains stable when both schemes are applied.

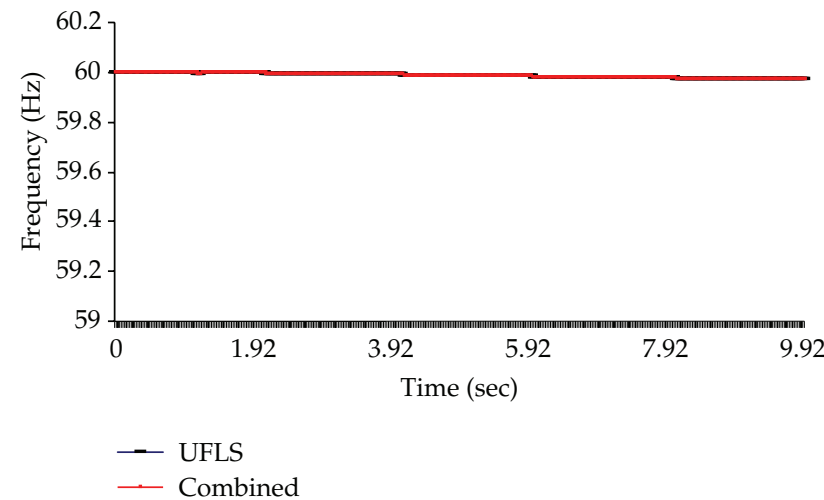

Figure 16: Average frequency responses when both schemes are applied. 
in a power system and is based on an equivalent inertia representing the total inertia of the generators located in the area. By assuming that all the generators in an area are coherent following a disturbance, it is assumed that an equivalent single large machine is representing all the generators in the area. The results proved that the proposed area-based COI-referred rotor angle index can accurately determine the transient stability state of the system when compared to the stability results evaluated by the individual rotor angles. The new TSI negates the need to assess all the generators rotor angles in a power system, and, therefore, rapid TSA of the whole system can be achieved. In addition, the results obtained show that the area-based COI-referred rotor angle index is able to determine the weakest area in a power system due to a fault. The IEEE 39-bus is considered to verify the effectiveness of the new TSI. Furthermore, an improved TSC method called the combined UFLS and generator tripping scheme is proposed. It is known that UFLS remains to be an important control strategy for mitigating transient instabilities. However, the main concern of UFLS is to determine the amount of load that needs to be shed in order to bring back the system to its stable state. The amount of shed load is greater when severe faults occur in a power system. The proposed method has attempted to reduce the amount of load shed in which slight changes are made in the stages of the conventional UFLS by including generator tripping in the first-stage. The generator to be tripped for the first-stage is identified by using the individual COI-referred rotor angle of generators in the affected area in which any generator in the area that goes out of step the earliest will be chosen as the generator to be tripped for the first-stage of the proposed scheme. The performance of the combined control scheme is compared with the conventional UFLS scheme, and it is noted that less load is shed when the proposed method is employed compared to the conventional UFLS. The results also show that the angle deviation of the affected area in the power systems is lower and more subtle when the combined UFLS and generator tripping scheme is applied which indicates that lower stress is exerted on the generators.

\section{References}

[1] P. Anderson and A. Fouad, Power system Control and Stability, McGraw Hill, Singapore, 2nd edition, 2003.

[2] M. K. Khedkar, G. M. Dhole, and V. G. Neve, "Transient stability analysis by transient energy function method: closest and controlling unstable equilibrium point approach," Journal of the Institution of Engineers (India): Electrical Engineering Division, vol. 85, no. 2, pp. 83-88, 2004.

[3] H. Sakaguchi, A. Ishigame, and S. Suzaki, "Transient stability assessment for power system via Lur'e type Lyapunov function," in Proceedings of the IEEE Power Systems Conference and Exposition (PES '04), pp. 227-232, October 2004.

[4] A. M. Miah, "A new method of transient stability assessment by using a simple energy margin function," in Proceedings of the 2nd International Conference on Electrical and Computer Engineering, pp. 24-27, 2002.

[5] G. Li and S. M. Rovnyak, "Integral square generator angle index for stability ranking and control," IEEE Transactions on Power Systems, vol. 20, no. 2, pp. 926-934, 2005.

[6] A. Padilha and E. F. Denis, "Transient stability indices from a hybrid approach," IEEE Porto Power Tech Proceedings, vol. 2, 5 pages.

[7] D. Ernst, D. Ruiz-Vega, M. Pavella, P. M. Hirsch, and D. Sobajic, "A unified approach to transient stability contingency filtering, ranking and assessment," IEEE Transactions on Power Systems, vol. 16, no. 3, pp. 435-443, 2001.

[8] K. W. Chan, Q. Zhou, and T. S. Chung, "Transient stability margin assessment for large power system using time domain simulation based hybrid extended equal area criterion method," in Proceedings of the 5th International Conference on Advances in Power System Control, Operation and Management, vol. 2, pp. 405-409, 2000. 
[9] K. W. Cheung, "An improved transient stability index for dynamic security assessment using a marginally unstable injection (MUI) approach," in Proceedings of the IEEE Power Engineering Society Winter Meeting, vol. 2, pp. 931-936, 2000.

[10] M. H. Haque, "Novel method of finding the first swing stability margin of a power system from time domain simulation," IEE Proceedings-Generation, Transmission and Distribution, vol. 143, no. 5, pp. 413-419, 1996.

[11] I. Kamwa, J. Beland, and D. Mcnabb, "PMU-based vulnerability assessment using wide- area severity indices and tracking modal analysis," IEEE PES Power Systems Conference and Exposition, vol. 10, no. 1, pp. 139-149, 2006.

[12] L. Le-Thanh, T. Tran-Quoc, O. Devaux et al., "Hybrid methods for transient stability assessment and preventive control for distributed generators," in Proceedings of the Conversion and Delivery of Electrical Power and Energy Society General Meeting, vol. 7, pp. 1-6, July 2008.

[13] A. L. Bettiol, Y. Zhang, L. Wehenkel, and M. Pavella, "Transient stability investigations on a Brazilian network by SIME," in Proceedings of the 4th International Conference on Advances in Power System Control, Operation and Management, vol. 1, pp. L1-L6, 1997.

[14] G. Ziegler, Numerical Distance Protection: Principle and Applications, Publicis Corporate Publishing, Erlangen, Germany, 1st edition, 1999.

[15] N. Amjady and S. F. Majedi, "Transient stability prediction by a hybrid intelligent system," IEEE Transactions on Power Systems, vol. 22, no. 3, pp. 1275-1283, 2007.

[16] S. B. Yusof, G. J. Rogers, and R. T. H. Alden, "Slow coherency based network partitioning including load buses," IEEE Transactions on Power Systems, vol. 8, no. 3, pp. 1375-1381, 1993.

[17] M. A. Pai, Energy Function Analysis for Power System Stability, Kluwer Academic Publishers, Boston, Mass, USA.

[18] P. Kundur, "Power system stability," in Power System Stability and Control, L. G. Grigsby, Ed., pp. 7-17-10, CRC Press, New York, NY, USA, 2007.

[19] T. Tomšič, G. Verbič, and F. Gubina, "Revision of the underfrequency load-shedding scheme of the Slovenian power system," Electric Power Systems Research, vol. 77, no. 5-6, pp. 494-500, 2007.

[20] A. A. M. Zin, H. M. Hafiz, and W. K. Wong, "Static and dynamic under-frequency load shedding: a comparison," in Proceedings of the International Conference on Power System Technology (POWERCON '04), vol. 1, pp. 941-945, November 2004.

[21] H. Seyedi and M. Sanaye-Pasand, "New centralised adaptive load-shedding algorithms to mitigate power system blackouts," IET Generation, Transmission E Distribution, vol. 3, no. 1, pp. 99-114, 2009.

[22] N. Perumal and A. C. Amran, "Automatic load shedding in power system," in Proceedings of the National Power Engineering Conference, vol. 12, pp. 211-216, 2003.

[23] D. Prasetijo, W. R. Lachs, and D. Sutanto, "New load shedding scheme for limiting underfrequency," IEEE Transactions on Power Systems, vol. 9, no. 3, pp. 1371-1378, 1994.

[24] G. G. Karady and J. Gu, "A hybrid method for generator tripping," IEEE Transactions on Power Systems, vol. 17, no. 4, pp. 1102-1107, 2002. 


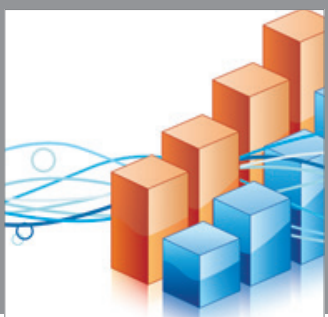

Advances in

Operations Research

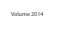

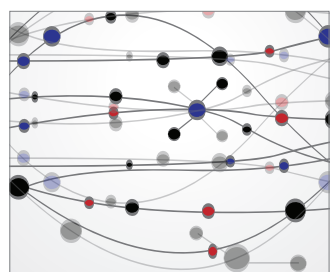

\section{The Scientific} World Journal
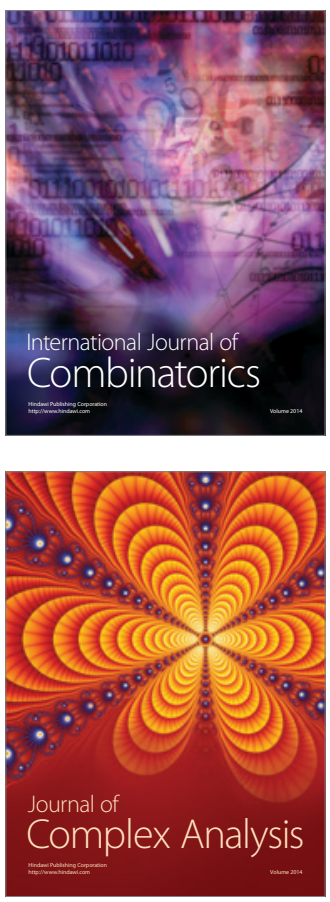

International Journal of

Mathematics and

Mathematical

Sciences
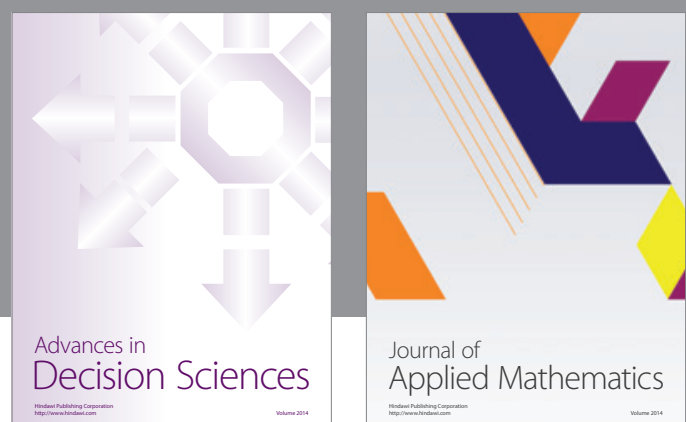

Journal of

Applied Mathematics
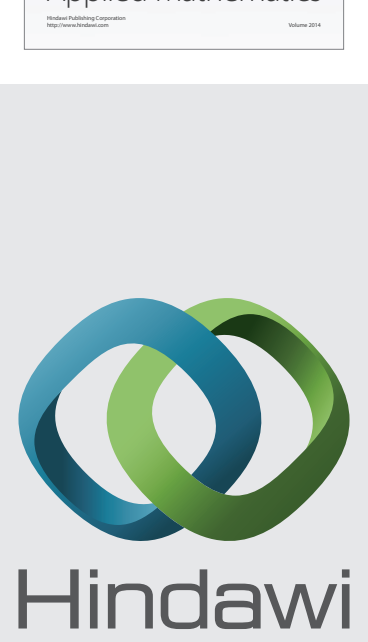

Submit your manuscripts at http://www.hindawi.com
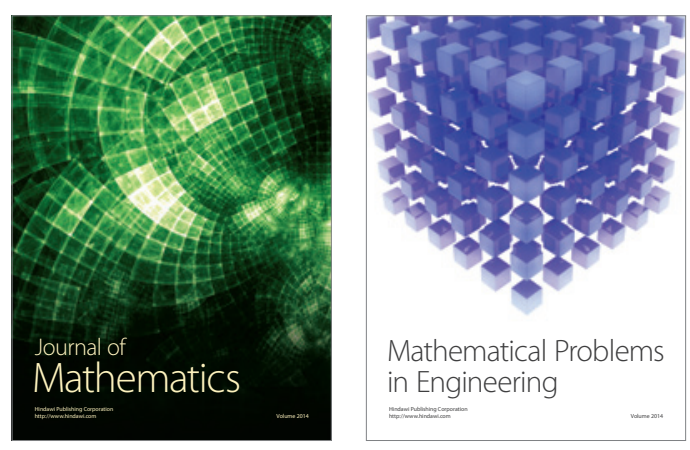

Mathematical Problems in Engineering
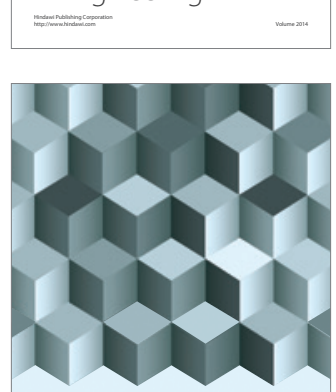

Journal of

Function Spaces
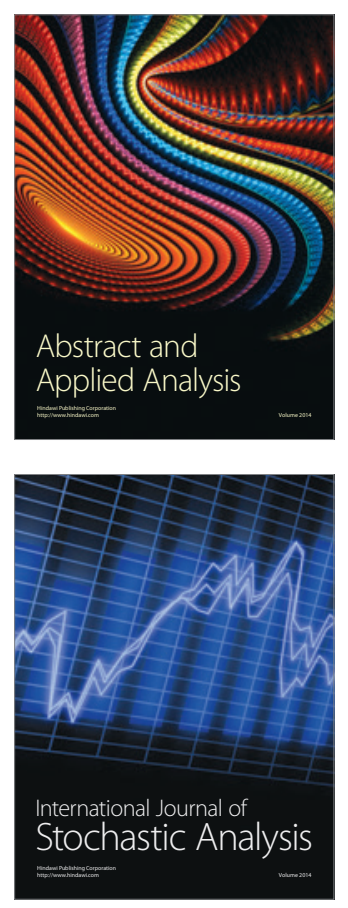

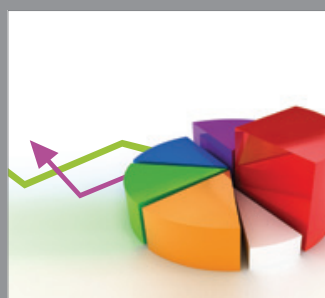

ournal of

Probability and Statistics

Promensencen
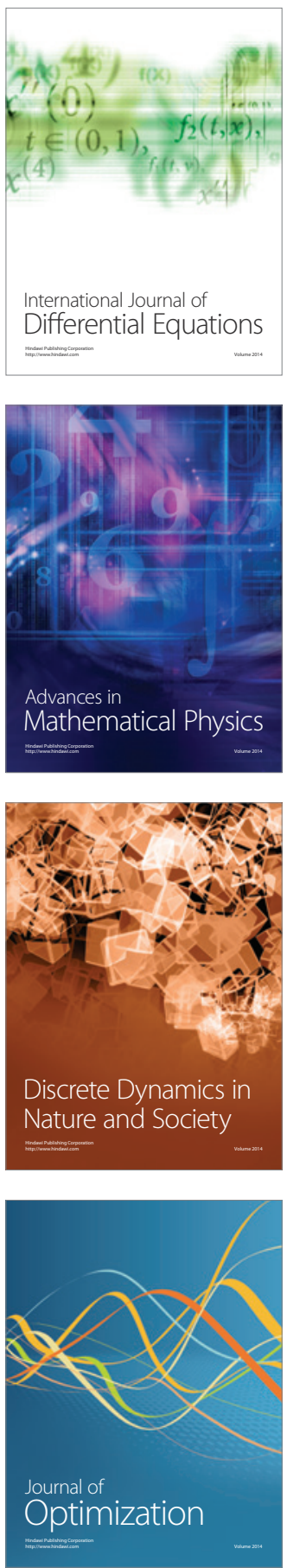